\title{
UNA DEDICACIÓN A JÚPITER EN LA BETURIA: LOS YACIMIENTOS DE LAS CASAS DEL SEJO (SEGURA DE LEÓN, BADAJOZ)
}

\author{
POR
}

\author{
LUIS BERROCAL-RANGEL * \\ Universidad Autónoma de Madrid
}

ANDRÉS OYOLA FABIÁN *

I.N.B. Eugenio Hermoso de Fregenal de la Sierra

\section{RESUMEN}

Presentamos, en estas páginas, nuevos documentos epigráficos que, analizados en su contexto arqueológico, aportan interesantes apreciaciones sobre la religiosidad de las poblaciones indígenas de la Beturia céltica en momentos iniciales del período romano. Con ello se avanza en la comprensión del grado de complejidad étnica subyacente tras los célticos del SO., así como en su religiosidad, definiendo un locus sacer liber consagrado a una divinidad indígena sincretizada con Júpiter, junto a una posible nueva dedicación a Ataecina.

\section{SUMMARY}

In theses pages we try to develop some approaches to Religion and Ethnicity between the Celtic peoples of SouthWest Iberia in the early Roman period (Ist century B.C. I Ist century A.D.), according to new epigraphic and archaeological evidence. On this line, we will try to define a new sacred place, in an open air site, dedicated to a deity, Anca[...]is, linked with Jupiter, and a possible new dedication to Ataecina.

\section{LOCALIZACIÓN Y DESCRIPCIÓN DE LOS YACIMIENTOS}

Dentro del programa de investigaciones sobre el patrimonio arqueológico del SO. extremeño, que desarrollamos desde inicios de los años ochenta en coordinación con la Dirección del Patrimonio de la Junta de Extremadura, pudimos localizar en Abril de 1994 dos yacimientos de especial interés en el término de Segura de León, provincia de Badajoz.

Identificados con los topónimos Casas del Sejo 1 y 2 , respectivamente, se emplazan en las faldas septentrionales de la Sierra de la Martela ${ }^{1}$, cuyo pico

* Queremos agradecer, especialmente, los comentarios, críticas y sugerencias recibidas de los profesores Javier de Hoz y Juan Manuel Abascal en la lectura e interpretación de este texto.

${ }^{\prime}$ Coordenadas $38^{\circ} 6^{\prime} 14^{\prime \prime} \mathrm{N}-6^{\circ} 28^{\prime} 15^{\prime \prime} \mathrm{O}$ (GreenwichHoja 897-II, 1:25.000 del MTN. de España). principal, a 812 m s.n.m., está ocupado por un castro protohistórico y romano, con poco más de hectárea y media de extensión (Berrocal-Rangel 1992: 305).

A mediados de la década pasada este lugar fue objeto de una intervención arqueológica a causa de la aparición de unas conocidas placas áureas de técnica orientalizante y temática céltica. Dos campañas de urgencia permitieron documentar niveles de ocupación prerromanos que acaban en época imperial, conservando fundamentalmente un carácter indígena, con materiales itálicos (Enríquez y Rodríguez Díaz, 1988; Berrocal, 1989).

Posteriormente, en las faldas de esta serranía, hemos localizado numerosos materiales constructivos que, como en los parajes de El Regío (Los Regidos) o Juanadame ${ }^{2}$, indican un denso poblamiento de época romana en estas tierras, regadas por el arroyo ardileño de El Sejo (fig. 1).

Así, al nordeste del castro, Casas del Sejo 1 se muestra como un área de unos $1000 \mathrm{~m}^{2}$ con numerosos fragmentos de tégulas y ladrillos, junto con sillares graníticos utilizados para la construcción de las cercas modernas que limitan el lugar. La presencia central de un conjunto de muros enterrados en forma de un gran edificio, con planta rectangular de $10 \times 20 \mathrm{~m}$ de longitud y anchura, se intuye bajo los taludes del terreno, con la prudencia obligada por la imposibilidad de proceder a su excavación ${ }^{3}$.

\footnotetext{
2 En esta finca fue localizada una necrópolis al roturar las cercanías del silo del cortijo, hace más de una década. Sus restos fueron recogidos por su propietaria, $D^{\mathbf{a}}$ María Luisa Sánchez García, profesora de Historia del I.B. "Eugenio Hermoso" de Fregenal de la Sierra, a quien agradecemos la información. Desgraciadamente sólo contamos con su testimonio, porque los materiales, algunos ungüentarios de vidrio y vasos cerámicos, fueron destruidos y perdidos tras un desgraciado accidente de tráfico, ocurrido inmediatamente después de su aparición, según testimonios recogidos por A.O.F.

${ }^{3}$ El lugar y los referidos elementos nos fueron notificados por D. Juan Medina Montero.
} 

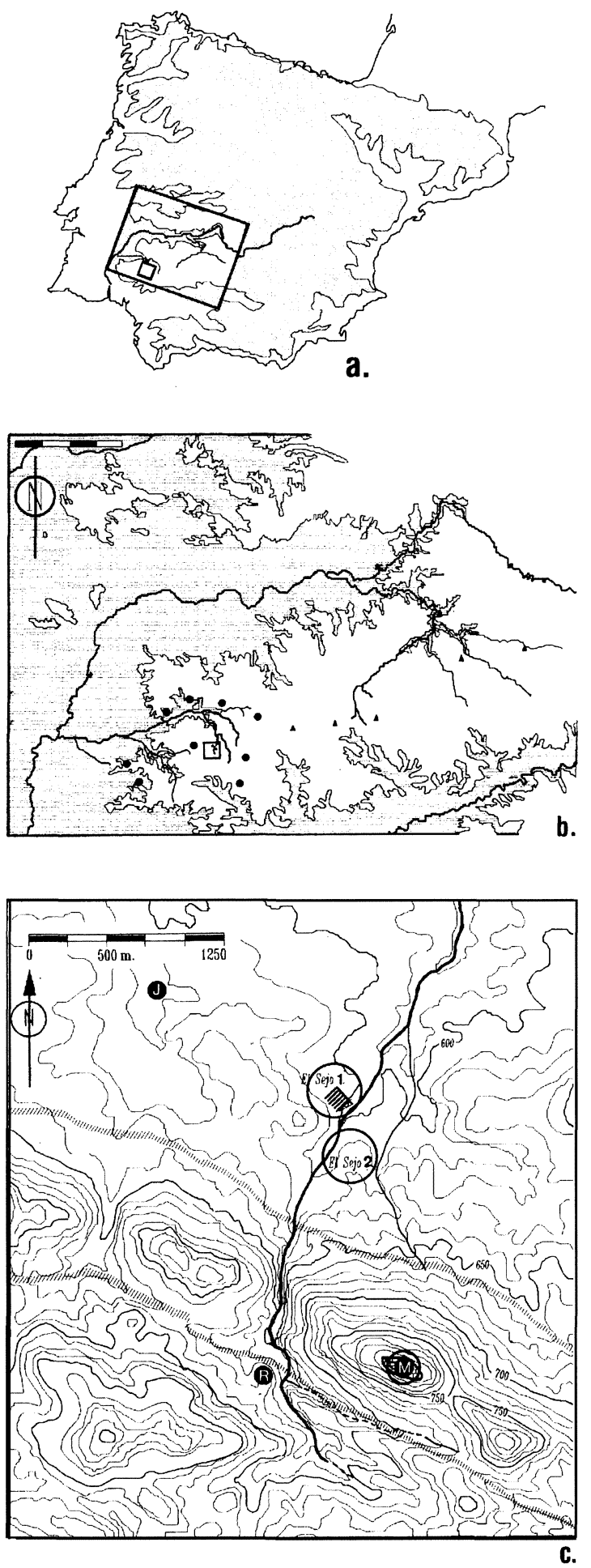

Fig. 1.-a. Emplazamiento de las Casas del Sejo en la Baeturia celticorum; b. ๑: oppida célticos, $\mathbf{\Lambda}$ : oppida túrdulos; c. Entorno de Casas del Sejo: M (castro de la Martela), J (necrópolis de Juanadame) y R (villa del Regío). Dibujo de Luis Berrocal.
Algo más al sur, Casas del Sejo 2 se ubica como el anterior entre frondosos bosques de alcornoques y numerosas fuentes, y correntías como la que les da nombre, que vierten sus aguas en el río Ardila y, por éste, en el Guadiana.

En general estos parajes muestran un territorio tan agreste como rico, restos de lo que fue una extensa y poblada propiedad de la familia Medina Aparicio, de Segura de León, hoy dividida en numerosas parcelaciones repartidas entre sus descendientes ${ }^{4}$.

Entre éstas, definidas por viejas paredes de piedra que tortuosamente se adaptan al terreno, se localizan pequeñas casas, cochineras y corrales de idéntico aparejo, entre los que se encuentran dispersos, aprovechados como dinteles, jambas y sillares de esquina, los citados restos arqueológicos. De ellos, en Casas del Sejo 2 llamó nuestra atención la presencia de un ara o cipo de cuerpo prismático y con decoraciones y molduras. Es utilizada como asiento junto a una puerta de las citadas casas, propiedad de $\mathrm{D}^{\mathrm{a}}$. Carmen Medina Maya.

\section{EL ENTORNO EN ÉPOCA REPUBLICANA E IMPERIAL}

Los estudios centrados sobre el poblamiento antiguo de la comarca han permitido conocer en profundidad el desarrollo histórico de este territorio durante los años previos e iniciales de la presencia romana en la cuenca del Ardila, en los que en principio parecen fecharse los dos yacimientos.

En tal sentido, el grueso de la documentación arqueológica procede principalmente de poblados relativamente cercanos, como El Castrejón de Capote (Higuera la Real) o Los Castillejos 2 (Fuente de Cantos), ambos en las mismas estribaciones sudoccidentales de la provincia pacense. Por ellos, y por las excavaciones de urgencia realizadas en el castro de La Martela, en la Sierra de El Coto (Nertobriga), en el castillo templario y villa romana de Pomar de Jerez de los Caballeros (¿Seria?), en el castillo de Burguillos del Cerro o en el poblado de La Ermita de Belén, así como por las prospecciones intensivas sobre los Cantamentos de la Pepina, San Sixto, Guruviejo, o sobre Batalla del Pedruégano, entre otros yacimientos, se ha podido confirmar la propuesta inicial que García Iglesias planteó sobre el emplazamiento de la Baeturia Celticorum en estos territo-

4 Directamente emparentados con uno de nosotros, L.B.R., a quien $\mathrm{D}^{\mathrm{a}}$ María del Carmen Maya Medina mostró la inscripción que se estudia a continuación. 
rios (1971) y que, hace unos años, vinimos a identificar con la cuenca del río Ardila (Berrocal-Rangel, 1988-1989).

Ya en los albores de la Era Cristiana, su personalidad fue destacada por la naturaleza específica de sus gentes, creídos de origen celtibérico, y con una entidad étnica que fue ampliamente reconocida (Plinio, Nat. Hist., III, 113-114) y que ha dejado suficientes restos en la arqueología del Suroeste como para proceder a su comprensión y confirmación (Berrocal-Rangel, 1994 y 1996, e.p.; otras aportaciones en Velázquez y Enríquez, eds., 1995).

Además, según Estrabón y Plinio estos pueblos vivían en «aldeas» y hablaban y adoraban a dioses que los diferenciaban de los pueblos más meridionales y señalaban el supuesto origen mencionado (Berrocal-Rangel, 1992, 70-72). Debían de explotar importantes recursos ganaderos, junto con el control y manipulación de los minerales que cruzaban la Beturia, bien procedentes de los importantes distritos del Noroeste peninsular (Alvarez Martínez, De la Barrera y Velázquez, 1985, 140), como de los pequeños yacimientos mineros comarcales (Berrocal-Rangel, 1995-a).

En tal sentido, Casas del Sejo se imbrica en las rutas que, presumimos, fueron usadas en esta Antigüedad prerromana y romana (Berrocal-Rangel, 1994, 223-227). Así, frente al mismo yacimiento, se localiza una vía homónima, tramo del Camino Viejo de Segura a Cabeza la Vaca de León y prolongación de la Real Cañada Leonesa Occidental (García Martín et alii, 1991, 434-437), conocida en documentos archivísticos locales como «Soriana» (Oyola, 1993, 18).

Esta relación, y la especial orografía que supone la Sierra de la Martela, permiten asegurar una disposición idónea para el control del tránsito de mercancías, disposición que se ha visto corroborada por la definición de una línea de poblamiento prerromano, republicano y alto-imperial que une La Martela con los castrejones de Bodonal, Batalla del Pedruégano y Cantamentos de la Pepina, a través del castillo de Segura de León, para proseguir, tras éstos, al norte del cauce del Ardila (Berrocal-Rangel, 1992, 256; Berrocal et alii, 1996, e.p).

Tal dedicación estratégica, que suponemos de naturaleza comercial y defensiva, se comprende en la clara vocación ganadera y forestal del territorio (VV.AA., Expl. Mapa Provincial de Suelos, 1972). Sobre este tema, el trabajo desarrollado por uno de nosotros en el marco de su tesis doctoral (A.O.F.) ha venido a demostrar la importancia que, desde los tiempos medievales, tiene la ganadería bovina en las riberas del Ardila, tanto la trashumante y transtermi- nante como la, no en menor proporción, estabulada (Berrocal-Rangel, 1996, 53 y nota 101).

\section{LOS ELEMENTOS ARQUEOLÓGICOS}

Proceden en su totalidad de las investigaciones superficiales que hemos realizado durante los últimos años, muchos ya conocidos por los dueños de las diferentes fincas.

En razón de la naturaleza del soporte y de la funcionalidad general distinguimos tres grupos:

1. Materiales cerámicos como fragmentos de ladrillos y tégulas: son relativamente escasos, quizá porque el paraje ha sido intensamente ocupado durante los tiempos más recientes.

2. Materiales arquitectónicos en piedra: son los más destacados, por razones de su capacidad para la reutilización y conservación. Todos ellos son elementos constructivos tallados básicamente en granito. Con una reserva lógica, por no poder proceder a su remoción al estar usados en paramentos y puertas de casas y corrales, responden a cuatro categorías:

2.1. Sillares lisos, cúbicos o prismáticos, tallados en granito y con tamaños que pueden considerarse monumentales.

2.2. Elementos constructivos con restos específicos de talla y encaje, documentados en una ocasión como sendas jambas de un portillo de Casas del Sejo 2. De ellas, la primera presenta una forma paralelepípeda de dos caras cuadradas, de las que la única visible muestra una clara anathyrosis periférica y lateral (Adam, 1984, 53), de manera que sus medidas exteriores son de $95 \times 55 \times 27 \mathrm{~cm}$ con un rebaje de $45 \times 27 \times 32 \mathrm{~cm}$. Esta pieza habría sido diseñada, en principio, para ofrecer como frontales al menos dos de sus caras estrechas. Frente a ella, un imponente sillar prismático de $68 \times 35 \times 60 \mathrm{~cm}$ muestra en su cara exterior dos oquedades paralelas de $12 \times 7 \mathrm{~cm}$ y $5 / 7 \mathrm{~cm}$ de profundidad, que responden a los huecos utilizados por pinzas de un mecanismo de elevación, de forma que la pieza pudo disponerse con esta cara hacia arriba (fig. 2).

2.3. Fustes de columnas se reconocen en dos piezas de Casas del Sejo 2, de 38 y $80 \mathrm{~cm}$ de longitud y entre 27 y $30 \mathrm{~cm}$ de diámetro, respectivamente, con secciones que no son completamente circulares. Puede pensarse que las dos proceden de la misma columna, aunque se encuentran separadas una decena de metros entre sí. El mayor de los fragmentos es utilizado como umbral de la puerta junto a la que se colocó el ara. Una pieza de fuste de semicolumna, con mayor tamaño, se localiza en Ca- 


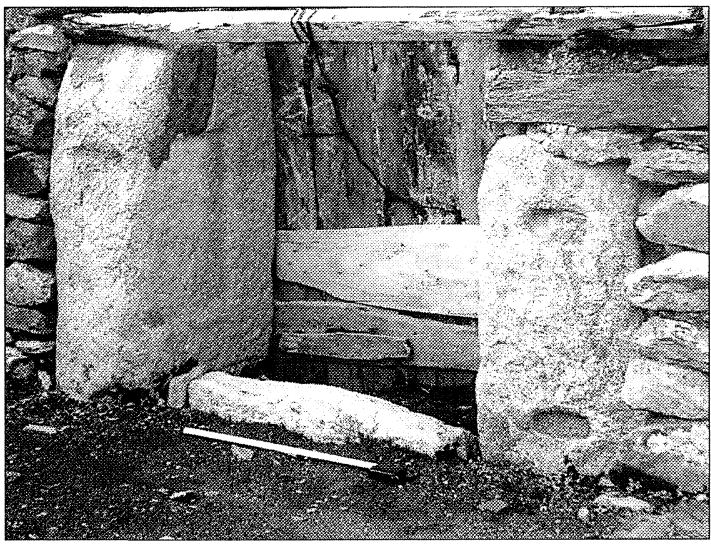

Fig. 2.-Elementos constructivos con restos de talla y encaje de Casas del Sejo 2. Fotografía de Luis Berrocal.

sas 1 , junto a una cornisa descrita a continuación. Sus medidas máximas son de $100 \times 60 \times 40 \mathrm{~cm}$.

2.4. Un fragmento de cornisa o de arquitrabe, de considerables dimensiones $(120 \times 80 \times 45 \mathrm{~cm})$, correspondiente a un elemento de esquina, tallado en granito (fig. 3).

3. Ara con inscripción: procede de Casas 2, en la misma clase de granito y con aparente ausencia de decoración, fuera de unas simples molduras que se documentan en sus extremos superior e inferior. Sus dimensiones son $52 \times 42 \times 30 \mathrm{~cm}$ en altura, anchura y grosor, mientras el campo epigráfico se

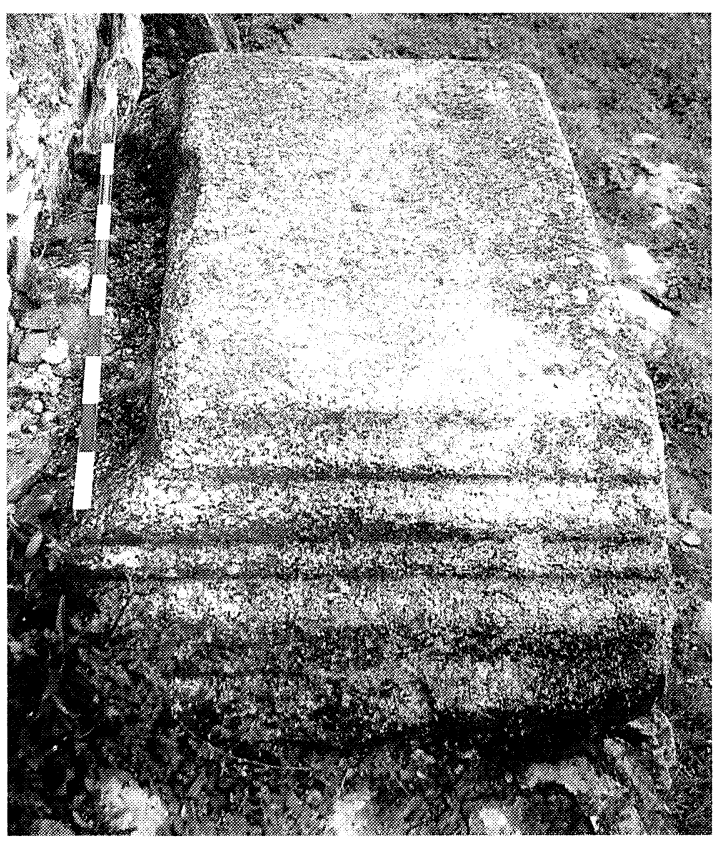

Fig. 3.-Fragmento de cornisa o arquitrabe en esquina, procedente de Casas 1. Fotografía de Luis Berrocal. limita a $35 \times 21 \mathrm{~cm}$. En éste se puede leer, con cierta dificultad por el grado de erosión, cuatro líneas en latín, con toscos caracteres y el punto como signo de interpunción:

Texto Altura de las letras
en $\mathrm{cm}$

\begin{tabular}{|c|c|}
\hline Iovi-Anca & 4,5 \\
\hline [..]i.Clovti & $4 / 4,5$ \\
\hline $\begin{array}{l}{[. . . .] \text { mici } \cdot f(\text { ilius }) \cdot} \\
\mathrm{v}(\text { otum }) \cdot](\text { ibens }) \cdot \mathrm{a}(\text { nimo }) \cdot \mathrm{s}(\text { oluit }) \cdot\end{array}$ & $\begin{array}{c}4 \\
3 / 3,5\end{array}$ \\
\hline
\end{tabular}

\section{ESTUDIO DEL EPÍGRAFE (figs. 4 y 5)}

Líneas 1-2: Iovi muestra una clara dedicación a Júpiter, emplazada en el primer vocablo del texto y con una realización más cuidada por parte del lapicida. No en balde es el término mejor conservado y de más fácil lectura. Sus letras, capitales, son de regular factura, entre las que destaca una "O" de forma subcuadrangular que podría implicar una fecha temprana para este testimonio sacro, uno más de los que ratifican la abundante propagación del culto a Júpiter en Extremadura, favorecida por la existencia de tradiciones religiosas de origen indoeuropeo comunes a pueblos romanos e hispanos.

Mayor dificultad presenta el segundo vocablo, Anca/[.. ]i, desgraciadamente desgastado en algunas

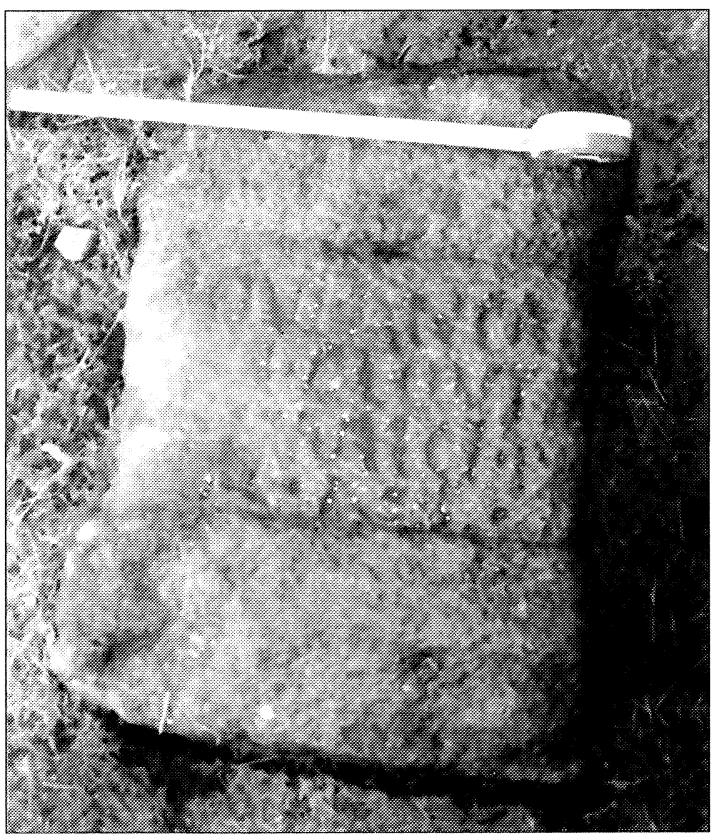

Fig. 4.- Inscripción de Casas del Sejo. Fotografía de Rafael Caso Amador. 


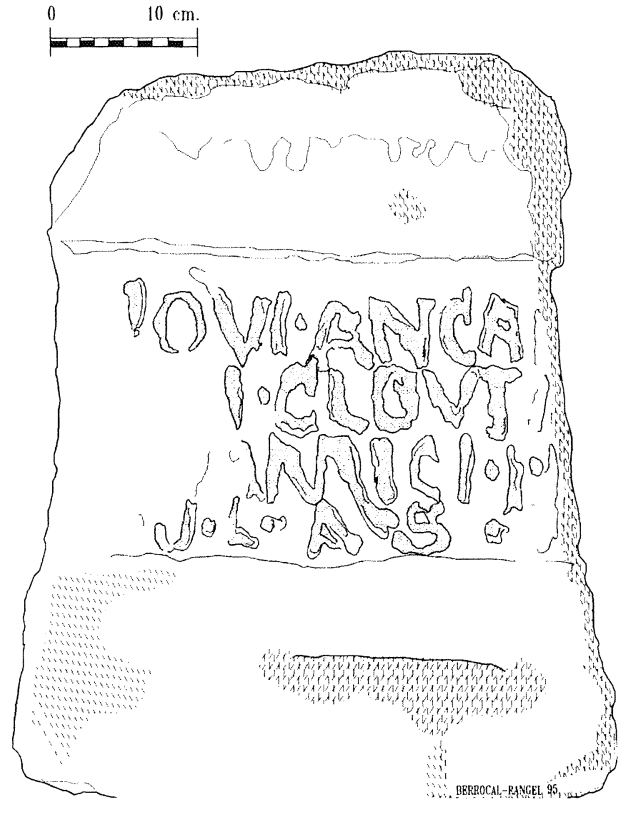

Fig. 5.- Inscripción de Casas del Sejo, con dedicación lovi Anca[.. ]i, quizá Anca[st]i, de un Cloutio. Digitalizado a partir de calco. Luis Berrocal.

de sus letras por el roce de la cuña que aseguraba la función actual del ara como asiento. La identificación segura de la "i" final nos daría un posible dativo y, por lo mismo, un teónimo, aunque esta vez de aparente adscripción indígena. En tal caso, se observaría un ejemplo de sincretismo religioso que, de nuevo, abogaría por la antigüedad relativa de esta inscripción.

La existencia de un Anderoni sincretizado con Iovi, en un epígrafe localizado en Galicia (Blázquez, 1975, 28; CIL II 2598) nos presenta una relación muy semejante, aunque en este caso se trataría de un derivado del radical *andh-, con un registro antroponímico muy bien conocido en el Noroeste y en Lusitania, donde destacamos un Andami hallado en Abertura, Trujillo (Palomar Lapesa, 1957, 35).

Sin embargo, la lectura de epígrafe del Sejo, Anca-, nos inclina más hacia otros paralelos, ampliamente conocidos en la linguística indoeuropea en forma de derivados del radical *ank-, doblar (Albertos, 1966, 23 ss.).

Entre ellos, los antropónimos son especialmente abundantes en el Suroeste céltico y en la Lusitania romana, como Anceitus y Ancetus (p.e., Aldeia dos Palheiros, Marvâo, Idanha-a-Velha, Monte Velo, Trujillo, etc.). Además, interesa el tema en Ang(Angetus, en Abertura, Trujillo; Angeiti, en Villar, Cáceres), porque se reconoce como teónimo en la forma Angefici (Cáparra, CIL II, nº 809: Magilo/
L...Govti f(ilius)/ ara(m) Angef/ici? f(aciendum) c(uravit), dios con nombre acabado en -ico, característico en el panteón indígena de la Lusitania y Gallaecia, y que debe relacionarse con el antropónimo Angetius (Blázquez, 1975, 28).

Este teónimo presenta, sin embargo, ciertas reservas en su interpretación, dada la dificultad de su lectura en el ara de Cáparra y su clara relación con los antropónimos referidos. Quizá por ello ha sido obviado en obras posteriores, incluso del mismo Blázquez (1983 y 1986; De Francisco, 1989; García Fernández-Albalat, 1990, etc., no por Abascal Palazón, 1994). Pero son conocidas las ambivalencias y "préstamos" entre teónimos, antropónimos, hidrónimos e, incluso, topónimos (p.e., en el bien estudiado caso de "Salamanca" por De Hoz, 1986, 42, y 1993, 371-374)

La existencia de una deidad indígena, de naturaleza occidental, con la raíz *ank- es plausible, es-pecialmente porque la encontramos en el nombre de la divinidad Ancamna, venerada sobre todo en la localidad de Deva (Chester, Inglaterra) aunque con trascendencia sobre tierras centroeuropeas, como demuestran sus dedicatorias en el santuario a Mars-Lenus de Trier/Tréveris, Alemania (Hatt, 1989, 164). De la misma manera, la dea Ancasta aparece citada epigráficamente en Inglaterra, en Clausentum (Bitterne, Southampton, CIL IV 4).

Estos testimonios nos permiten suponer la lectura de un Ivpiter Anca[..]is, quizá referido a la deidad de nombre Ancasta testimoniada en Britannia, en una fórmula resultante de un sincretismo similar a los casos del I(ovi) Assaeco hallado en Lisboa o del Ioveai Caeilobrigoi de Lamas de Moledo, ambos relacionados con estructuras suprafamiliares (Blázquez, 1975, 86). Dicho sincretismo nos parecería de carácter céltico o, al menos, indoeuropeo de ámbito occidental peninsular.

En esta línea, se alcanza mayor apoyo cuando se analiza en profundidad la naturaleza del dedicante de esta ara de El Sejo.

Líneas 2-3: El antropónimo indígena Clovti/[..], claramente relacionado con otros que comparten la raíz indoeuropea klev-, "oír" (en celta, *klutos-, "célebre", "conocido", "oído"...), está muy bien documentado en la Península Ibérica, con una significativa dispersión noroccidental (Palomar Lapesa, 1957, 66; Albertos, 1966, 90-91 y mapa 3; 1985, 279 y mapa 5): Trujillo (Cloti), Salamanca (Clov.T.L; Clovtia), Guimarâes (Clovitvs), Valença do Minho (Clvtimoni), Caldas de Reyes - Pontevedra- (Clovtai), Lugo (Clovtami), etc., proyectada hacia Mérida (Clovtiane; Clovatia) y, más allá, por el Suroeste céltico, tal como ya comentamos en pu- 
blicaciones anteriores (Berrocal-Rangel, 1992, 57 y fig. 5.2).

De todas ellas la forma más documentada es Clovti, en general en contexto de filiación, en genitivo, con ejemplos que salen del área reseñada en algún lugar como Espinosa de los Henares (Guadalajara; Hisp. Epig. 1989, I, 419). Por ello, y por el contexto general del epígrafe y la lectura más lógica para los términos siguientes, nos inclinamos por interpretarlo como un nominativo singular, Clovti[vs], referido al oferente del ara.

Entre sus paralelos, el más cercano, geográfica, cultural y contextualmente, se localizó en la misma comarca del Ardila, unos kilómetros más al Sur, en el término onubense de El Repilado. Nos referimos a una conocida inscripción funeraria que cita una relación de dedicantes con típicos nombres del Noroeste peninsular, entre los que destacamos un Talavivs Clovtivs [C]lovtai f(ilius) (Luzón, 1974, 295-296).

Precisamente esta inscripción fue dedicada a la memoria de un Anceitvs, de cognomen Límico, con filiación y castellum (Vaccei.f.Limicvs.c.Talabric.), en una fórmula antroponímica romanizada pero de clara naturaleza indígena. Se supone que tanto el difunto como sus dedicantes, que se autodenominan fratreseeivs, son de origen galaico, dada la tradicional localización bracaraugustana de los talabrigenses, aunque no excluimos la posibilidad de que pudieran ser etnónimos y topónimos repetidos entre los célticos de la Beturia, dado que son típica y tópicamente hispanoceltas (Berrocal-Rangel, 1992, 324; Albertos, 1990, 113).

La relación entre los Clovti de El Repilado y el citado en la lápida de El Sejo podría deducirse de la aproximación geográfica, de la comunidad del entorno y del antropónimo del difunto, Anceitvs, que recuerda evidentemente a nuestra propuesta de lectura del término Anca[.. ]i.

La interpretación más plausible para El Sejo nos inclina por Clovti[vs], en nominativo singular, fundados asimismo en su relación con los términos siguientes, [..]mici.f(ilius). Por esto mismo, no parece muy lógico que fuese un genitivo, porque en nominativo hace referencia al oferente del ara y da mejor explicación a la dimensión del campo epigráfico destruido en este lugar.

[..]mici plantea interrogantes obvios. Sin justificación válida, nos inclinamos por proponer la lectura [Li]mici que, pese a su apariencia gentilicia, sería antropónimo en genitivo singular, en contexto de filiación, porque una sigla aislada al final de la línea separada por signos de interpunción permite considerarla como abreviatura de f(ilius).
Tampoco puede descartarse otro nombre, como [A]mici, [A]nnici, [Fa]lmici o [Ga]mici (Abascal Palazón, 1994, 400 y comunicación personal), pero en el caso propuesto preferimos seguir la disposición de El Repilado, con una filiación similar, Vaccei-f(ilivs), del individuo "cognominado" Límico. De la misma manera, Abascal aborda un caso procedente de Horna (Guadalajara), que restituye como [Li]micvs, con un paralelo seguro en Alcalá de Henares (CIL II 3034). Pero, indica este autor, esta "opción... en la restitución del texto no implica una elección justificada" (Abascal y López de los Mozos, 1993, 272).

En suma, la utilización del nombre "Límico" como antropónimo indígena está atestiguado en El Repilado (Huelva) y en Alcalá de Henares y podría considerarse para los casos de El Sejo y Horna, ambos en territorios cercanos a los anteriores, respectivamente. Todo ello puede relacionarse con la existencia del étnico Límico, referido a conocidas poblaciones bracaraugustanas del Noroeste peninsular (TIR, $K-29$, s.v. LIMICI), pero su dispersión antroponímica es central y sudoccidental. No obstante, esta discordancia espacial no impide excluir su consideración de reflejo postrero de viejas relaciones indígenas que acabarían impregnando la misma antroponimia (por el contrario, en cierto sentido, la refuerza).

Líneas 3-4: Resuelven con una fórmula de tipo votum, frecuente en los epígrafes votivos hispanos (Iglesias, 1993, 308 y clave BV29.3; Blázquez y García Gelabert, 1988, 54, 164 y 169; González Rodríguez, 1986, 67). Aceptado [Li]mici.f(ilius), decidimos la solución L(ibens) y S(olvit).

La datación conjeturable a partir de criterios caligráficos y contextuales nos inclina a considerar una fecha del siglo I d. C., o un momento en todo caso algo más temprano, habida cuenta de los claros elementos indígenas que presenta el epígrafe y la importancia que, hasta mediados del siglo II d.C., muestra la arqueología romana de la comarca. Pero estos criterios sólo nos permiten una relativa aproximación a la datación del epígrafe.

\section{CONCLUSIONES ARQUEOLÓGICAS, LINGÜÍSTICAS Y EPIGRÁFICAS. CRONOLOGÍA}

En principio, los dedicantes de Casas del Sejo deben considerarse como integrantes de los pueblos célticos del Suroeste peninsular, que habitaban amplias comarcas del Alentejo portugués, tanto del interior (p.e., en torno a Pax Iulia -Beja-) como de 
la costa (p.e., Mirobriga Celticorum), así como al este del Guadiana, en la provincia de Badajoz y norte de Huelva, donde se emplazan estos yacimientos (Baeturia Celticorum: Berrocal-Rangel, 1989-1990; 1996, e.p.; Velázquez y Enríquez, eds., 1995).

Sobre pequeños castros, como el vecino cerro de La Martela, y en citanias de tamaño medio (cir. 5 ha), como la cercana Nertóbriga, sus patrones de poblamiento recuerdan la cita de Estrabón (Geog. 3.2.15) sobre sus costumbres de vivir en aldeas. Plinio informa de sus oppida y de su procedencia celtibérica y de su personalidad étnica, constatable en los nombres de sus «ciudades», creencias, costumbres y lengua (Nat. Hist. 113).

Pero pese a la contundencia de tal testimonio, una somera visión del panorama arqueológico prerromano que se desprende de las excavaciones y prospecciones abiertas en estos territorios permite constatar con facilidad que dichas poblaciones presentaban un trasfondo étnico mucho más complejo de lo que, en primer término, pudiera deducirse.

$\mathrm{Al}$ menos desde el siglo Iv a. C. muestran claros signos de identidad con substratos prerromanos del Duero Medio, en tierras después definidas como solar de vacceos antiguos (García-Bellido, 1993, e.p.; Berrocal, 1992, 285 y 1996, e.p., 94), previos a un impacto celtiberizador ${ }^{5}$. Consensuadamente, estas poblaciones no pueden considerarse celtibéricas (Lorrio, 1995; Romero Carnicero, Sanz Mínguez y Escudero, 1993; Mañanes, 1991).

En tal situación, la supuesta relación de origen recogida por Plinio sobre los celtas de la Beturia motivaría una lógica reserva interpretativa. Pero en momentos recientes hemos podido confirmar, con testimonios arqueológicos, la específica naturaleza del apelativo pliniano: ciertas asociaciones materiales de Capote, Vaiamonte y Herdade das Casas permiten afirmar la presencia de pequeños contingentes, sin duda elites de carácter militar procedentes de la Celtiberia que, a juzgar por dichos materiales y por la toponimia (Nertóbriga, Ségida, Arcobriga), serían de origen arévaco y belo (Berrocal-Rangel, 1995, 142-143 y 1996, e.p., 94-97).

Desde un planteamiento exclusivamente arqueológico, esta presencia se observa únicamente duran-

\footnotetext{
5 En este sentido coincidimos con la aproximación realizada por $\mathrm{M}^{\mathrm{a}}$ Paz García-Bellido desde enfoques numismáticos (1993-e. p.). Sus resultados destacan el singular comportamiento monetal que une a vacceos del Duero y célticos del Guadiana con el uso de un sistema pre-monetal con patrón en oro que se traduce en una ausencia de cecas y que podría reflejar un remoto origen común. En la misma línea hemos incidido en la vinculación de estas poblaciones del Suroeste a pequeñas explotaciones de placeres auríferos (BerrocalRangel, 1992, 83 y 238).
}

te el siglo II a. C., coincidiendo con la larga época de conflictos que acarreó la conquista romana del Suroeste peninsular. De su repercusión social, y del previo trasfondo hispanocelta que comprobamos al menos desde inicios del siglo Iv a. C., se comprende que Plinio achacase un origen celtibérico a estas poblaciones sudoccidentales, dando cumplida lógica a los testimonios que recogió en el siglo i d.C.

Vacceos y celtíberos configuraron, en diferentes modos, la identidad céltica de estos pueblos del Ardila y del Guadiana a lo largo de los últimos siglos del milenio, en épocas anteriores a su definitiva asimilación por el dominio romano.

Pero con éste, que fechamos a lo largo del siglo I a.C. a partir de los restos arqueológicos y numismáticos (Berrocal-Rangel, 1989-1990, 116-119 y 1992, 279), se manifiestan otros testimonios más difusos, como los referidos a los dedicantes de las inscripciones de Casas del Sejo, El Repilado y Riotinto. Las presencias de antropónimos y étnicos, como los Clo$v t i$ y talabrigenses en ellas citados, abogarían en épocas ya plenamente romanas por contingentes de similar adscripción indoeuropea pero, quizá, relacionados con un remoto origen noroccidental, y una dedicación específicamente minera.

Estas consideraciones, junto con la naturaleza indígena del teónimo y del nombre del dedicante de la inscripción de El Sejo, nos lleva a emplazar esta inscripción entre finales del siglo I a.C. y mediados del I d.C., como reflejo de una transición social lenta y compleja entre estas poblaciones del Suroeste, que comienzan, entonces, a ofrecer los primeros rasgos de un estado de romanización consolidado ${ }^{6}$.

Un exhaustivo análisis del potencial geológico de esta Beturia y de los restos arqueológicos relacionables permite demostrar que la base real de su consideración minera, de la que tanto se ha hablado en función exclusivamente de la singular cita dejada por Estrabón (Geog. 3.2.3), fue referida a las amplias tierras habitadas por los túrdulos, en el centro y este de la provincia de Badajoz, en los Pedroches cordobeses y en la Alcudia manchega, pero no a la supuesta minería céltica del Occidente extremeño, donde los abundantes recursos férricos fueron y son sólo aprovechables en algunos puntos concretos (p.e. Burguillos-Jerez, Cala y Valera). Los célticos

\footnotetext{
${ }^{6}$ Conclusión que se desprende de la clara aparición de materiales constructivos romanos, junto con la generalización de la escritura y algunos datos arqueológicos singulares en los que venimos trabajando: el depósito alto-imperial de Capote (Berrocal-Rangel, 1991; Berrocal-Rangel y Ruiz Triviño, eds., e. p.), junto con el recientemente conocido de San Pedro, de igual época. Los resultados contrastan con la tópica visión de una Beturia occidental romanizada en época republicana.
} 
de la Beturia se dedicaron en pequeña escala a labores metalúrgicas sobre estos recursos y sobre los del Noroeste, cuyo tránsito controlaban desde Jerez, Aroche y Aracena (Álvarez et alii, 1985, 140; Berrocal, 1995).

Los Clovti de El Sejo, El Repilado y Riotinto, sin embargo, parecen reflejar una presencia diferente, de dispersión más meridional y en relación con el potencial indudable de las minas de Riotinto, fuera ya de la Beturia. En esta localidad se documentan epigráficamente varios individuos pertenecientes al castellum talabrigense, que Albertos consideró galaicos bracaraugustanos $(1990,141)^{7}$.

Estos galaicos, en opinión de Blázquez, Albertos, Luzón o De Hoz, entre otros, serían mineros llegados a instancias de nuevos planes de explotación y control de los recursos de tal índole, esta vez promovidos por los romanos (De Hoz, 1995, 592).

En función de estos testimonios cabría relacionar los conocidos relieves de Riotinto con la representación de cabezas humanas coronadas con cuernos, atribuibles a figuraciones de divinidades galaico-lusitanas (Blázquez, 1975, 82-83; 1983, 262), sin duda extensibles a territorios occidentales habitados por vacceos y vettones. En la misma línea cabe considerar los testimonios onubenses del culto a Borea Cantibedoniensis (Blázquez y García Gelabert, 1988, 164-167; Piernaseca, 1980, 359).

Que tales cultos existieron en el Suroeste parece confirmarse con el Ivpiter Anca[..]is de El Sejo, cuya naturaleza sacra se refuerza por el carácter monumental, aunque rústico, de sus elementos arquitectónicos (p.e., la cornisa).

Con todo, se trataría de manifestaciones religiosas que se constatan en relación a esta tardía presencia, cuya novedad permite ser comprendida desde la consideración de divinidad tutelar de extranjeros que se le supone a Júpiter en la Península (Perea y Figueroa, 1991-1992), diferente a la religiosidad más difundida en el Suroeste, claramente definida por las conocidas advocaciones a Endovélico y Atecina.

Sobre este punto, aprovechamos la ocasión para divulgar un testimonio más en esta línea, procedente de la vecina localidad de Cabeza la Vaca de León (Badajoz). Se trata de una inscripción que, sobre un ara de granito, está reaprovechada como sillar de la fuente de la calle del Coso de dicha localidad (Girol y Aceitón, 1991). De nuevo con dificultad pueden distinguirse dos líneas, con el texto (fig. 6):

\section{[I]vlivs Fe/lix Do(minae) S(anctae)}

${ }^{7}$ Para su localización propone Ponte da Lima, Miño, por las inscripciones aparecidas. Un emplazamiento general en TIR, K-29, s.v. LIMICI.

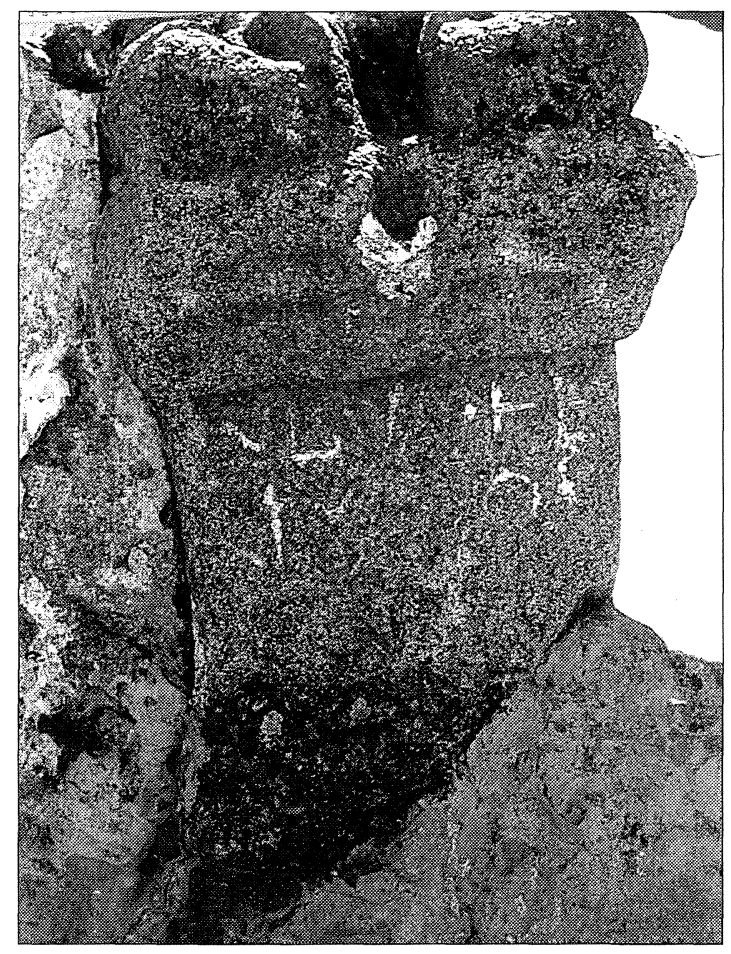

Fig. 6.--Inscripción de la Fuente del Coso, con dedicación a la Do(minae) S(anctae) [Ataecinae]. Fotografía de Rafael Caso Amador.

Sin indicio de fórmula funeraria alguna, la dedicatoria con los epítetos domina sancta puede relacionarse con alto grado de seguridad, tal como nos ha comentado el Dr. José Luis Ramírez, con la diosa Atecina (con la fórmula más completa, procedente de Santa Lucía del Trampal, dea domina sancta Turibrigense Ataecina: Abascal Palazón, 1995).

Pero en El Sejo documentamos un ejemplo de sincretismo indígena con Júpiter similar a los conocidos en tierras más septentrionales, de la Lusitania (Blázquez, 1983, 269; Redondo, 1986, 17 s.). Además su entorno muestra una naturaleza monumental de elementos constructivos que permite suponer la existencia de un espacio sagrado integrado en un ámbito natural, en un bosque, bajo una montaña y cruzado por un caudaloso arroyo, en definitiva, de un locus sacer liber (Lucas Pellicer, 1981, 238) a modo de nemeton, aunque romanizado y señalado con una construcción de estilo grecorromano cuyo emplazamiento suponemos en Casas del Sejo 1 (aquí, la abundancia de tejas, ladrillos, sillares y dolia contrasta con su escasez en Casas 2).

Ello no impide considerar la existencia de otro tipo de monumentos sacros, más acordes con el sincretismo reflejado en el epígrafe y la naturaleza de 
su dedicante. En tal sentido, junto con la obvia presencia de un arroyo con caudal poco menos que permanente (nacido bajo la vecina Segontia-SigûnsaGigonza: Berrocal-Rangel, 1994, 200), analizamos un destacado afloramiento cuarcítico a escasos centenares de metros hacia el Noroeste, conocido como Piedra del Herrero y cartografiado como Pavo Rayo ${ }^{8}$. Su impresionante aspecto, con una altura de diez metros, justificó que lo calificásemos de auténtico "menhir natural" en una publicación anterior.

Aunque en sus entornos inmediatos no hemos encontrado resto arqueológico alguno, su emplazamiento afrontado a la Sierra de la Martela, morfología y topónimos y la cercanía al testimonio epigráfico nos impiden olvidar la asociación del trueno y del rayo con el culto a Júpiter, y la consideración de esta deidad como numen loci de los montes y bosques que se le consagraron (Blázquez, 1983, 269, 290). Entre éstos cabe destacar, precisamente, el límico monte Lauroco (Pontevedra) y el monte Candan (Orense), con un Iovi Deo Candamo (Blázquez, 1983, 282-283), pudiendo reconocerse en nuestro término Anca[..]i una raíz que recuerda a los Ancares (León-Lugo).

Además cabe recordar la vieja dualidad céltica Júpiter-Marte, a menudo confundidos en Hispania (Blázquez, 1986, 11) y en el resto de la Europa céltica, asimilados a un "Marte indígena o protocéltico" (Hatt, 1989, 29; López Monteagudo, 1989). Por ello es posible que la presencia de un topónimo como La Martela no sea casual, ni que sus conocidas placas áureas muestren representaciones antropomórficas con motivos de fondo en forma de ruedas, glóbulos o discos, junto a cabezas de équidos (Berrocal-Rangel, 1989,281 ; 1992-145). Todos estos elementos remiten a una semántica que en contextos galos se consideraría típica y tópicamente taránica, específica del Dis Pater que fue la temprana tricotomía TaranisTeutates-Esus (Hatt, 1989, 40 y 150 s.).

¿Existió en el actual bosque de El Sejo un ámbito sagrado, un nemeton romanizado que, en cierto sentido, haría referencia a la Piedra del Herrero y al cerro principal de la Sierra de la Martela? En nuestra opinión, dada la clara dispersión occidental de los Clovti y la presencia de una divinidad indígena, cuya aparición en estas tierras confirma la extensión hacia el Suroeste de dichos teónimos, hay suficientes restos e indicios como para dar una respuesta afirmativa.

${ }^{8}$ El término podría considerarse un sugerente derivado de "pararrayo" pero, en verdad, debe hacer referencia al Padre García Borrallo, sacerdote segureño del siglo xviII (el Pa Borrayo, sic: R. Caso Amador, 1991: El caballo del Padre Borrallo, Rev. Fiestas del Cristo de la Reja, 11-13).
En conclusión, el epígrafe de Casas del Sejo vendría a aumentar la lista de testimonios que afirman la naturaleza indoeuropea y occidental de las poblaciones indígenas del suroeste peninsular, reforzando convergencias con un amplio noroeste, ya en momentos del período romano. Con ello se avanza en la comprensión del grado de complejidad étnica subyacente tras el gentilicio céltico con que sus habitantes eran conocidos, y que la arqueología ha definido como resultado de contingentes previos de vacceos y celtíberos. Además, en el Sejo se define un locus sacer liber, dedicado a una divinidad indígena, Anca[..]is, sincretizada con Júpiter.

\section{BIBLIOGRAFÍA}

Abascal Palazón, J. M., 1994: Los nombres personales en las inscripciones latinas de Hispania. Arqueología 1, Anejos Antigüedad y Cristianismo, II. Murcia.

Abascal Palazón, J. M., 1995: Las inscripciones latinas de Santa Lucía del Trampal (Alcuéscar, Cáceres) y el culto a Ataecina en Hispania, AEspaA, 68, 31-106.

Abascal Palazón, J. M.; López de los Mozos, J. R., 1993: Dos inscripciones inéditas de los territorios de Segontia y Ercávica, H. Ant., XVIII, 269278.

Adam, J. P., 1984: La construction romaine. Materiaux et techniques. París.

Albertos Firmat, M. L., 1966: La onomástica personal primitiva de Hispania. Tarraconense y Bética. Salamanca.

Albertos Firmat, M. L., 1990: Los topónimos en -briga en Hispania, Veleia, 7, 131-146.

Álvarez Martínez, J. M.; De la Barrera, J. L.; Velázquez, A., 1985: El tiempo antiguo, en M. Barrientos, E. Cerrillo y J.M. Álvarez, eds.: Historia de Extremadura, I, Badajoz, 101-180.

Berrocal-Rangel, L., 1988-1989: Hacia la definición arqueológica de la "Beturia de los célticos": la cuenca del Ardila, Espacio, Tiempo y Forma (Hom. Ripoll Perelló), II-1, 57-68.

BerRoCAL-RANGel, L., 1989: Placas áureas de la Edad del Hierro de la Meseta occidental, TP, 49, 279-291.

Berrocal-Rangel, L., 1991: Avance al estudio del depósito votivo alto-imperial del Castrejón de Capote (Higuera la Real, Badajoz), en J.J. Enríquez y A. Rodríguez Díaz, eds., I Jornadas de Prehistoria y Arqueología en Extremadura, ExtrA, II, Cáceres, 331-346. 
Berrocal-Rangel, L., 1992: Los pueblos célticos del Suroeste de la Península Ibérica. Extra Complutum 2.

Berrocal-Rangel, L., 1994: Oppida y castros de la Beturia céltica, en M. Almagro-Gorbea y A.M. Martín Brevo, eds., Castros y oppida en Extremadura. Extra Complutum, 4, 189-242.

BERROCAL-RANGEL, L., 1995-a: La Beturia: definición y caracterización arqueológica de un territorio prerromano, en Velázquez y Enríquez, eds., La Beturia: Celtas y Túrdulos, Cuadernos Emeritenses, 9.

Berrocal-Rangel, L., 1995-b: Indoeuropeos, célticos y celtíberos en el territorio extremeño. en L. Berrocal et alii, eds., Arqueología en Extremadura: 10 años de descubrimientos, ExtrA, IV, 123150.

Berrocal-Rangel, L., 1996, e.p.: La Beturia. Un territorio prerromano en el Guadiana. Badajoz.

Blázquez Martínez, J. M., 1975: Diccionario de las religiones prerromanas de Hispania. Madrid.

Blázquez Martínez, J. M., 1983: Religiones prerromanas. Primitivas religiones ibéricas, II. Madrid.

Blázquez Martínez, J. M., 1986: Sincretismo en la Lusitania romana. Manifestaciones religiosas en la Lusitania, I, Salamanca, 7-14.

Blázquez Martínez, J. M. y García Gelabert, M. P., 1988: Nuevas aportaciones a las religiones primitivas de Hispania. Espacio, Tiempo y For$m a$, II, 1, 153-183.

Enríquez Navascués, J. J. y Rodríguez Díaz, A., 1988: Campaña de urgencia en la Sierra de la Martela (Segura de León, Badajoz). ExtrA, I, Cáceres-Salamanca, 113-128.

Francisco Martín, J. de, 1989: Conquista y romanización de la Lusitania. Acta Salmanticensia, 58, Salamanca.

García Iglesias, L., 1971: La Beturia, un problema geográfico de la Hispania Antigua, AEspA, XLIV, 86-108.

García Fernández-Albalat, B., 1990: Guerra y religión en la Galicia y la Lusitania antiguas. La Coruña.

García Martín, P. et alii., 1991: Cañadas, cordeles, $y$ veredas. Valladolid.

García-Bellido, M. P., 1993, e. p.: Los ámbitos de uso y la función de la moneda en la Hispania republicana, en J. MANGaS (ed.), Coloquio hispano-italiano La crisis de la tardía república en Hispania e Italia (Toledo, 1993). Toledo.

García-Bellido, M. P., 1995: Célticos y túrdulos en la Beturia: documentos numismáticos, en A. VELÁzquez y J. J. Enríquez (eds.), Celtas y Túrdulos: La Beturia, Mérida, 257-292.
Girol, A. J. y Aceitón, L., 1991: Hallazgos romanos en Cabeza la Vaca. Rev. Fiestas de S. Benito y $N^{a}$ $S r^{a}$ de los Ángeles, 18-19.

GonZÁlez RodríGuez, M. C., 1986: Las unidades organizativas indígenas del área indoeuropea Hispania. Anejo Velia, 2.

Hatт, J. J., 1989: Mythes et dieux de la Gaule, Y. Les grands divinités masculines. París.

Hoz, J. de, 1986: La religión de los pueblos prerromanos de la Lusitania. Manifestaciones religiosas en la Lusitania, I, Salamanca, 31-49.

Hoz, J. de, 1995: Tartesio, fenicio y céltico 25 años después, Tartessos. 25 años después, 591-607, Jerez de la Frontera.

IgLEsias, F. J., 1993: Las fórmulas en las inscripciones latinas votivas de la Hispania romana: ensayo lógico estadístico, H.Ant., XVII, 279-320.

López Monteagudo, G., 1989: Avance sobre el culto a Marte indígena en la Península Ibérica. Anejos Gerión (Homenaje S. Montero), II, 328-332.

Lorrio Alvarado, A. J., 1995, Celtas y celtíberos en la Península Ibérica, en A. Velázquez y J. J. ENRíQuez (eds.), Celtas y túrdulos: la Beturia, Mérida, 77-126.

Lucas Pellicer, M. R., 1981: Santuarios y dioses en la Baja Época Ibérica. La Baja Época de la Cultura Ibérica, Madrid, 239-296.

LuZón NoguÉ, J., 1974: Romanización. Huelva: Prehistoria y Antigüedad. Madrid.

Mañanes Pérez, T., 1991: Arévacos, en L. Solana (ed.), Las entidades étnicas de la Meseta Norte de Hispania en época prerromana. Anejos Hispania Antiqva, 211-234.

Oyola Fabián, A., 1993: Segura de León. Monumentos e Historia. Fregenal de la Sierra.

PalOMAR LAPESA, M., 1957: La onomástica personal prelatina en la antigua Lusitania. Salamanca

Perea, S. y Figueroa, E., 1991-1992: "Hospitivm Privatvm" y "Ivs Libertorvm", Veleia, 8-9, 219230.

Piernavieja, P., 1988: "Denudator gimnasi v.s. Arescu”. Homenaje a García y Bellido, IV, 359 s.

Redondo Rodríguez, J. A., 1986: La religión grecoromana en el Sureste cacereño a través de los testimonios epigráficos. Manifestaciones religiosas en la Lusitania, I, Salamanca, 15-29.

Romero Carnicero, F.; Sanz Mínguez, C.; EscudeRo, Z., eds., 1993: Arqueología vaccea. Estudios sobre el mundo prerromano en la Cuenca media del Duero. Valladolid.

T.I.R. K-29, 1991, Madrid.

Velázquez, A. y Enríquez, J. J., eds., 1995: Celtas y túrdulos: la Beturia. Monografías Emeritenses, 9. Mérida. 